\title{
An evaluation of the NHS England Youth Forum
}

Whiting LS et al (2016) An evaluation of the NHS England Youth Forum. Nursing Standard. 3I, 2, 45-53. Date of submission: 7 July 20l5; date of acceptance: 6 October 2015. doi: I0.7748/ns.20l6.el02I3

\section{Lisa Whiting}

Professional lead, children's nursing

University of Hertfordshire, Hatfield, Hertfordshire, England

\section{Sheila Roberts \\ Senior lecturer, children's nursing, University of Hertfordshire, Hatfield, Hertfordshire, England \\ Jenni Etchells \\ Clinical facilitator, \\ children's nursing, Hertfordshire Community NHS Trust, Hemel Hempstead, Hertfordshire, England}

\section{Kath Evans}

Experience of care lead, Maternity, Infants, Children and Young People Nursing Directorate, NHS England, London, England

\section{Alice Williams \\ Public engagement lead, Patients and Information Directorate, NHS England, Leeds, England}

\section{Correspondence}

l.whiting@herts.ac.uk

@kathevans2

\section{Open access}

\begin{abstract}
Aim

To use qualitative data collection approaches to enhance insight and understanding of the NHS England Youth Forum, including its role, value and potential effects.

\section{Method}

A qualitative evaluation research approach was used. Two focus groups were conducted: one with five young people from the NHS England Youth Forum and another with five members of the Adult Reference Group that supports the forum's work. Individual semi-structured interviews were undertaken with four employees of NHS England and the British Youth Council who had a central role in the development and implementation of the forum.

\section{Findings}

The members of the NHS England Youth Forum were participating in an extensive range of activities, and their work is having a direct and positive influence on the provision of healthcare services. The day-to-day management of the forum, in terms of personnel, time and commitment, should be acknowledged.
\end{abstract}

\section{Conclusion}

Young people are not only highly capable of participating in decision making related to healthcare, but also want to be involved and value the opportunity.

\section{Keywords}

children, children's services, evaluation, NHS England, qualitative research, research, young people, youth forum

ONE OF THE seven core tenets of the NHS is to put patients at the heart of everything it does (NHS Choices 2015a). The NHS Constitution (Department of Health (DH) 2015) outlines the principles that should be embedded at every level of the NHS, in both adult and children's services. Despite this, Professor Sir Ian Kennedy stated in his review, Getting it Right for Children and Young People, that NHS services for children and young people have a low priority (Kennedy 2010). This view has been supported by others, including the Chief Medical Officer (DH 2013a), whose 2012 report made several recommendations in relation to listening to children and young people. It emphasised that although there was evidence of continued effort by many professionals, as well as some effective practice, there was a need for 'us to go further' (DH 2013a).

\section{Literature review}

Several strategies have been designed and implemented to ensure that the voices of children and young people can be heard in healthcare services. At a national level, Healthwatch England was introduced as part of the Health and Social Care Act 2012, as a direct result of Equity and Excellence for Children (DH 2010). Healthwatch England is the national consumer champion in health and social care. It is committed to capturing the voices of consumers and 
Conflict of interest

None declared

\section{Review}

All articles are subject

to external double-blind

peer review and checked

for plagiarism using

automated software

\section{Online}

For related articles visit

the archive and search

using the keywords.

Guidelines on writing for

publication are available

at: journals.rcni.com/r/

author-guidelines ensuring that they are heard by those commissioning, delivering and regulating healthcare services (Healthwatch 2016). Since 2010, the National Children's Bureau (NCB), funded by the $\mathrm{DH}$, has worked with Local Involvement Networks (LINks) and local Healthwatch England pathfinders to champion engagement with children and young people (NCB 2013a). In addition, guidance has been published about the engagement of children and young people in Healthwatch England (Healthwatch England 2013). Despite this, analysis of the 75 Healthwatch England pathfinder projects showed that only five mentioned children and young people (Young Minds 2012, Davies and Clancy 2013). Furthermore, a 2013 report by the NCB found that local Healthwatch England services were not supported to involve children and young people and were not equipped to champion their voices (NCB 2013b). Young Minds (2012) suggested that if children and young people are not involved from the outset, it will be difficult for them to participate in organisational structures that have already been established. However, no formal report has yet provided the views of children and young people in relation to Healthwatch England.

Another national strategy to engage children and young people's voices is The NHS Family and Friends Test (NHS Choices 2015b, NHS England 2016). In 2013, the Patient Experience Network stated that this test would be available in all clinical areas where children and young people receive care and treatment by 2015 (Patient Experience Network 2013). The Friends and Family Test is a way of gathering feedback about the patient experience and driving improvement in the NHS; it aims to ensure patients have a positive experience of care, in line with Domain 4 of the NHS Outcomes Framework (DH 2013b). Separate engagement guidance is available to promote patients with particular needs, including children and young people. For example, the monkey character in the NHS Institute for Innovation and Improvement Primary School Resource Pack (Monkey Wellbeing 2014a) has been developed to offer developmentally appropriate Friends and Family Test questions that enable children's voices to be heard (Monkey Wellbeing 2014b). This is important because children and young people have previously been excluded from patient surveys (Hargreaves and Viner 2012).

In local areas, initiatives such as You're Welcome: Quality Criteria for Young People Friendly Health Services (DH 2011) are being encouraged, and in 2014 the Children and Young People's Health Outcomes Forum (2014) made a renewed pledge to implement this. The You're Welcome initiative sets out principles to help commissioners and service providers improve the suitability of healthcare services for young people (DH 2011) and has been operationalised throughout the country (DH 2007, 2011). However, because there does not appear to be a national evaluation planned, this could lead to inconsistencies in the uptake of specific initiatives and the commitment to embed young people's voices at the heart of the NHS. However, it is promising that the You're Welcome initiative (DH 2011) has undergone expansion since it was launched in 2005 and there has been continued reinforcement of its benefits (DH 2010, Kennedy 2010, Davies 2013).

In the NHS, effective practice to involve and engage children and young people remains limited. Kennedy (2010) emphasised that there is no shortage of policies, guidance and frameworks released by the $\mathrm{DH}$ in relation to children and young people, yet difficulties remain in translating these into action. In 2013, the Children and Young People's Health Outcomes Forum published a response to the consultation on Refreshing the Mandate to NHS England 2014/2015, which again emphasised that children and young people 'struggle to get their voices heard, and are not involved in decisions about their own health'. To redress this balance, the NHS England Youth Forum was launched in March 2014.

\section{The NHS England Youth Forum}

The NHS England Youth Forum aimed to not only meet the main objectives of 
involving children and young people in healthcare services, but also to act as a role model for other organisations, such as clinical commissioning groups. The British Youth Council (BYC) was given the responsibility of managing the NHS England Youth Forum.

The purpose of the NHS England Youth Forum is to (Healthcare Quality Improvement Partnership 2015):

»Listen to young people's experiences and ideas for improvement.

»Work with a diverse range of young people who can use their perspectives and experiences of healthcare services to help us understand and improve services.

»Seek advice from young people about national programmes of work in the NHS. At the time this study was undertaken, the NHS England Youth Forum comprised 20 young people, aged 15-21 years.

They communicated with each other through pre-arranged residential meetings held three times a year and via a closed Facebook page (supported and monitored by a BYC employee). To reach a wider group of children and young people, an open Facebook page and Twitter account (www.facebook.com/NHSEnglandYF; @NHSYouthForum) were used. Outside of the pre-arranged residential events, the young people were invited to a variety of activities where they were able to engage with senior healthcare personnel and policy makers. The University of Hertfordshire was commissioned and financed to undertake a qualitative evaluation of the NHS England Youth Forum between October 2014 and March 2015.
Aim
The aim of this study was to use qualitative data collection approaches to enhance insight and understanding of the NHS England Youth Forum, its role, value and potential effects, by ascertaining the views and perceptions of:
"Young people who were members of the NHS England Youth Forum.
»Members of the Adult Reference Group that supports the NHS England Youth Forum. The Adult Reference Group comprises representatives from

a range of youth organisations, such as Whizzkids and the NCB. The group meets every 6 to 8 weeks and acts in an advisory capacity to the NHS England Youth Forum.

"NHS England and BYC employees who have a central role in the organisation and implementation of the NHS England Youth Forum.

\section{Method}

An evaluation research approach was adopted. Moule and Goodman (2014) identified different approaches to evaluation research: goal-orientated, experimental, goal-free, utilisation focused, economic and mixed method. A goal-free strategy, focussing on whether the needs of individuals and localities are being met, was selected because this enables the researcher to 'probe aspects of the intervention that are not precise or easily measured' (Moule and Goodman 2014). In goal-free evaluation research, it is common practice for personnel who are external to the project to conduct the work because this enhances objectivity, as was the case in this study.

\section{Participant recruitment}

A purposive sampling technique was used to recruit the participants, who were five young people from the NHS England Youth Forum, five members of the Adult Reference Group and four employees of NHS England and the BYC. Young people were recruited via the BYC dayto-day coordinator of the NHS England Youth Forum and members of the Adult Reference Group were recruited via their chairperson. To identify the relevant employees, a 'good informant' approach was used. Morse (1994) stated that this enables the selection of the participant 'who has the knowledge and experience the researcher requires, has the ability to reflect, is articulate, has the time to be interviewed, and is willing to participate in the study.'

\section{Data collection tools}

Two focus groups were conducted: one with five young people from the NHS England Youth Forum and the other 


\author{
KEY POINT \\ 'The young people's \\ commitment to the work \\ of the NHS England Youth \\ Forum was evident and \\ it required a substantial \\ amount of their personal \\ time. They participated \\ in a range of activities, \\ including residential \\ weekends, national and \\ local events, responding \\ to emails and engaging in \\ the Youth Forum Facebook \\ pages and Twitter account'
}

with four members of the Adult Reference Group. The focus groups were run by the research team and were 60 and 47 minutes in duration, respectively. Guidelines for the focus groups were developed, together with a set of prompt questions to maintain consistency and facilitate data collection.

Semi-structured individual interviews were undertaken with the four employees of NHS England and the BYC. All interviews were conducted by a member of the research team, with interviews lasting between 32 and 68 minutes. An interview checklist was prepared that identified practical arrangements and areas to be clarified with each participant, as recommended by Stewart et al (2007). Each interview and focus group was recorded using a digital-audio recorder and all participants consented to its use. No supplementary written notes or memos were taken during the interviews or focus groups to minimise potential distractions.

Focus groups have many of the advantages of individual face-to-face interviews, such as the ability to explore the participants' experiences. In addition, focus groups are time efficient, enhance interaction and have been used with young people successfully (Ormerod and Newton 2013). Stewart et al (2007) suggested that focus groups are an ideal qualitative data collection approach to use at the start of a study because the information gleaned can then be explored in more depth using other methods, such as interviews. This strategy was adopted in the study, with the two focus groups being conducted before the four individual face-to-face interviews.

\section{Data analysis}

The three qualitative data sets were analysed using Braun and Clarke's (2006) six phases of thematic analysis, since this is a flexible method that enables the identification and reporting of themes or categories. Chiovitti and Piran (2003) advocated that the participants' actual words are used when reporting findings; it was felt that this strategy would value the participants' contributions and facilitate the portrayal of their views.

\section{Ethical approval}

Ethical approval was obtained from the University of Hertfordshire Health and Human Sciences ethics committee. All participants were provided with information sheets and completed a consent form. Since parental consent had been obtained for those participants who were under 18 years of age to participate in NHS England Forum activities, it was considered appropriate for them to self-consent to this research. To ensure confidentiality, participants were given a pseudonym, and personal data was kept as a hard copy as well as on an encrypted memory stick that was stored in a locked cabinet. Care was taken when reporting the findings and when describing participants to prevent them being identified.

\section{Findings}

\section{Young people}

The young people's commitment to the work of the NHS England Youth Forum was evident and it required a substantial amount of their personal time. They participated in a range of activities, including residential weekends, national and local events, responding to emails and engaging in the Youth Forum Facebook pages and Twitter account. Some event invitations were sent directly to the young people, but the majority were sent via the BYC day-to-day coordinator, who ensured that the activities were selected appropriately.

The young people explained that at early NHS England Youth Forum meetings, they had identified three areas to focus on in the first year: mental health, communication between clinicians and young people, and sexual health. The residential weekends primarily addressed these areas, primarily from a national perspective. These weekends were also used to plan other events such as the Children's Commissioner's Takeover Day, which provided children and young people with the opportunity to work with adults for the day and be involved in decision-making related to healthcare. The participants felt that their involvement in the planning of this event made sure that 'Takeover Day is 
really something which works practically and isn't tokenism' (Tristan).

The young people stated that an important aspect of the NHS England Youth Forum role was collaboration with others so that the work of the forum was disseminated; Tristan referred to this as a 'ripple effect'. Therefore, as well as the national focus, the members of the forum also had links with local initiatives and events. For example, Harry explained that he had recently been involved in the development of local preCAMHS (Child and Adolescent Mental Health Services) facilities, which involved liaising with a range of personnel including young people and youth workers. The participants were confident that their work with the NHS England Youth Forum had been recognised and acknowledged, and provided examples of this:

'One of the young people mentioned that they went into hospital and they went to the Patient Advice Liaison Service, and they wanted to complain and they turned around and went "no, you're under 18. Get your mum to complain." So after a conversation with the appropriate important person they changed the guidance to specifically say that under $18 \mathrm{~s}$ are permitted to complain.' (Sam)

The young people suggested how others could become involved in the NHS England Youth Forum and share their thoughts and opinions. These suggestions included accessing the forum Facebook page or Twitter feed, participating in local activities and developing links with schools. The young people also mentioned the challenges associated with participation in the forum; these were primarily related to travel distances and the logistics of managing the number of events they were involved in. In addition, they were aware that the age range of the membership (15-21 years) did not include younger children. However, it was generally agreed that the involvement of younger children could present difficulties:

'In the past we've looked at the Gillick case and the Fraser guidelines and things like that around the ability to consent to medical treatment, so obviously, you know, younger young people may find that a bit overwhelming.' (Harry)

However, Vijay commented on a Young Health Champions event he had been involved in and said that children and young people between the ages of 4 and 5 years and up to 18 or 19 years had attended; therefore, he felt that the younger age range was participating to some extent, via associated activities.

\section{Adult Reference Group}

Participants from the Adult Reference Group explained how they engaged with the NHS England Youth Forum. This was primarily via the meetings held on a 6 to 8 weekly basis, as well as the facilitation of workshops, involvement in residential weekends and disseminating information to a wider audience of young people through their own networks. Despite the challenges of accommodating the NHS England Forum work alongside their main employment duties, the participants expressed a strong commitment to their role in the Adult Reference Group.

All the participants affirmed that the NHS England Youth Forum agenda was being driven by the young people and that they had 'invested in it personally' (Emma). There was a positive perception of the work of the forum, and this was for two main reasons. First, the participants felt that the young people themselves were able to benefit in terms of 'confidence building' (Lindsay), 'skills development' (Lindsay), and 'empowerment' (Emma). Second, it was clear that the group felt that the forum was providing a 'platform' (Kimberley) for young people to liaise with senior personnel and that it had a direct and positive effect on healthcare services. The participants from the Adult Reference Group thought that the skills the young people had developed meant they had been able to take their work and ideas back to their local areas.

There was agreement that, although there was some wider engagement of children and young people who were
KEY POINT

'The young people stated that an important aspect of the NHS England Youth Forum role was collaboration with others so that the work of the forum was disseminated; Tristan referred to this as a 'ripple effect'. Therefore, as well as the national focus, the members of the forum also had links with local initiatives and events' 


\section{KEY POINT}

'The participants discussed the achievements of the

NHS England Youth Forum; in particular, the positive recognition that the forum had received from senior healthcare personnel and policy makers was felt to be of fundamental importance' not part of the NHS England Youth Forum through events such as Takeover Day, this could be further developed. Examples of how to facilitate broader engagement included enhancing social media communication and the use of the networks of children and young people that the Adult Reference Groups had access to. For example, one member of the group was responsible for children and young people involvement in Sense (a national charity that supports and campaigns for deafblind children and adults) and another member also had a senior role within the NCB.

\section{Employees}

The participants who were employees of NHS England and the BYC described two important factors in the inception of the NHS England Youth Forum: documents such as the Health and Social Care Act 2012 and the participants' personal commitment to the engagement of children and young people:

'So with my remit and being a children's nurse by background I was very aware that we needed to ensure that the voice of children and young people needed to be amplified right across the whole of the NHS... NHS England needed to be seen as a system role model and that we couldn't expect local area teams, regional teams, clinical commissioning groups or providers of services to be truly embedding young people's voice unless we were doing it as a national organisation.' (Jess)

Hannah explained that the young people had been able to meet with national directors and that 'when young people can have a direct conversation with somebody, that's when influence happens.' The NHS England Youth Forum had also provided an opportunity to ascertain the views of young people in relation to topical and current health issues:

\section{'If the Prime Minister makes an} announcement that A\&E [Accident and Emergency] will be reviewed... it gives us some space in the model to say "actually, for the next time we meet we want to bring this up on the agenda".' (Hannah)

The participants discussed the achievements of the NHS England Youth Forum; in particular, the positive recognition that the forum had received from senior healthcare personnel and policy makers was felt to be of fundamental importance.

The employees were not always able to quantify how much of their time was spent supporting the NHS England Youth Forum activities, but it was clear that there had been significant and ongoing investment. The BYC day-to-day coordinator spent the most time supporting the young people, at approximately 8 hours per week. This person worked with them via the residential weekends, the Twitter and closed Facebook accounts, as well as email correspondence. Other aspects of forum support were less visible:

'If you send a young person to a conference, there's all the time that goes into risk assessing that, booking the travel. If they're under a certain age they need to be accompanied and it all adds up in time and money.' (Paul)

The participants also had some concerns about the number of events that the young people were invited to:

'I mean I literally get bombarded with [requests] on a daily basis.' (Beth)

The employees questioned whether this approach was fulfilling the forum's aims:

'So one of our challenges is we've got more requests than we can fulfil... you know, you can't just ring us on a Tuesday and say "I've got a meeting next Tuesday and I want a young person". Because this isn't a tick-box exercise.' (Hannah)

In addition, it was suggested that undertaking too many forum activities could have an effect on other aspects of the young people's lives, especially school or university work. 
The employee participants recognised that the future development of the NHS England Youth Forum was not established fully: 'NHS England's [Youth Forum] model is quite unique internationally' (Jess); therefore, there was no previous work to use as a basis and gain insight from. Some actions had already been undertaken to publicise the work of the forum, including the presence of the NHS England Youth Forum at important events, such as the NHS England Expo, and the production of a short film for the NHS England website (NHS England Youth Forum 2015, Reporters' Academy 2016). However, there were other suggestions for the future:

'Our next challenge is how do we build and support our regional teams and area teams to do something similar; that's next year's programme.' (Hannah)

Another aspect that was recognised as an area for development was the provision of feedback to the young people. Although there were some mechanisms in place during residential weekends and in online discussions, there was a suggestion that 'we could definitely do better' (Jess). Funding, politics and the complexity of the NHS were issues raised by employee participants. It was felt that the financial side of the NHS England Youth Forum was important 'because people will challenge us about the spending of public money' (Hannah). It was accepted that 'value for money' (Hannah) was necessary for the Forum to be sustainable. Overall, there was a strong feeling that the NHS England Youth Forum had been productive:

'I think it's exceeded what it was set up to achieve. It's vastly exceeded.' (Beth)

\section{Discussion}

In 1991, having ratified the United Nations Convention on the Rights of the Child, the UK government made a commitment to adhere to the convention. The child's voice was one of the major themes, with articles 12 and 24 of particular importance in terms of guiding healthcare professionals.
Article 12 focusses on the child's right to say what they think, and Article 24 relates to the child's right to high quality healthcare (UNICEF 2005). The NHS England Youth Forum was launched in 2014, 10 months after the establishment of NHS England. Although the forum is still in the early stages of development, this study has shown tangible examples of its work; for example, the young people have devised a series of posters reflecting Youth Rights in Health Care (NHS England 2015), with the aim of distributing these widely to healthcare professionals and influencing local policy. Ongoing funding will enable the forum to further develop so that a broad range of children and young people can benefit. However, the provision of clearer documentation of the activities being undertaken would be useful; this would not only provide a record of the forum's achievements, but also would help identify the staff and financial resources required to facilitate future work.

There is growing recognition that listening to children and young people's views and experiences of healthcare develops their confidence, improves cooperation and helps them cope better with treatment (Lansdown 2011). The findings from this research study emphasise that young people benefit personally from being involved in decision-making, and more importantly they want to be consulted. Kennedy's (2010) report reiterated the need to ensure 'that young people in particular are heard and listened to'. This study has identified that the strategies required to facilitate this, in terms of personnel, time and commitment, should not be underestimated. Young people are a vulnerable group and it is imperative that they continue to receive appropriate support to protected from any excessive demands that could be placed on them.

It is now recognised that young people 'possess information and knowledge that policy makers require' (Tisdall and Davis 2004). Through a wide range of networking events, the NHS England Youth Forum has enabled young people to engage with and influence senior personnel in health policy
KEY POINT

'It is now recognised that young people 'possess

information and knowledge that policy makers require' (Tisdall and Davis 2004), Through a wide range of networking events, the NHS England Youth Forum has enabled young people to engage with and influence senior personnel in health policy development' 
development. However, it is essential that young people are provided with feedback about their involvement, since failing to do so could be a deterrent to future participation. Traditionally, older children were consulted in terms of policy making (Burfoot 2003, Hill et al 2004), and this is primarily the case with the NHS England Youth Forum. Perhaps the 'ripple effect' (Tristan) will enable permeation to younger age groups in all aspects of healthcare.

\section{Limitations}

Five young people from the NHS England Youth Forum and five members of the Adult Reference Group were able to participate in each of the focus groups; therefore, the views presented might not be wholly representative of their colleagues. This evaluation research used qualitative data collection approaches (focus groups and interviews); the use of quantitative methods could have provided a different perspective.

\section{Conclusion}

The NHS England Youth Forum has developed rapidly, and this is a result of the commitment of all those involved, especially the young people who have given their time. This research has confirmed that young people are not only extremely capable of participating in decision making in relation to healthcare, but also that they want to be involved. Therefore, it is imperative that this approach is emulated by others so that, in the future, there is 'no decision about me, without me' (DH 2012).

\section{References}

Braun V, Clarke V (2006) Using thematic analysis in psychology. Qualitative Research in Psychology. 3, 2, 77-101.

Burfoot D (2003) Children and young people's participation: arguing for a better future. Youth Studies Australia. 22, 3, 44-51.

Children and Young People's Health Outcomes Forum (2013) Final Response to the Consultation on Refreshing the Mandate to NHS England: 2014-2015. www.gov.uk/ government/uploads/system/uploads/ attachment_data/file/307474/Forum_-_ Recommendations_NHS_England_ mandate_Sept_14.pdf(Last accessed: 12 August 2016.)

Children and Young People's Health Outcomes Forum (2014) Report of the Children and Young People's Health Outcomes Forum 2013-2014. www.gov.uk/ government/uploads/system/uploads/ attachment_data/file/307011/CYPHOF_ Annual_Report_201314_FORMAT_V1.5.pdf (Last accessed: 12 August 2016.)

Chiovitti RF, Piran N (2003) Rigour and grounded theory research. Journal of Advanced Nursing. 44, 4, 427-435.

Davies SC (2013) Annual Report of the Chief Medical Officer 2012. Our Children Deserve Better: Prevention Pays. Department of Health, London. www.gov.uk/government/ publications/chief-medical-officersannual-report-2012-our-children-deservebetter-prevention-pays (Last accessed: 12 August 2016.)
Davies F, Clancy M (2013) Surveying child patients in emergency care is possible. Emergency Medicine Journal. 31, 4, 262.

Department of Health (2007) You're Welcome Quality Criteria: Making Health Services Young People Friendly. The Stationery Office, London.

Department of Health (2010) Achieving Equity and Excellence for Children: How Liberating the NHS Will Help us Meet the Needs of Children and Young People. www.gov.uk/ government/uploads/system/uploads/ attachment_data/file/216652/dh_119490.pdf (Last accessed: 12 August 2016.)

Department of Health (2011) You're Welcome: Quality Criteria for Young People Friendly Health Services. www.gov.uk/government/ uploads/system/uploads/attachment_data/ file/216350/dh_127632.pdf (Last accessed: 12 August 2016.)

Department of Health (2012) Liberating the NHS: No Decision About Me, Without Me. The Stationery Office, London.

Department of Health (2013a) CMO's Annual Report 2012: Our Children Deserve Better. The Stationery Office, London.

Department of Health (2013b) The NHS Outcomes Framework 2014/15. www. gov.uk/government/uploads/system/ uploads/attachment_data/file/256456/ NHS_outcomes.pdf (Last accessed: 12 August 2016.)
Department of Health (2015) The Handbook to the NHS Constitution for England. www. gov.uk/government/uploads/system/ uploads/attachment_data/file/474450/ NHS_Constitution_Handbook_v2.pdf (Last accessed: 12 August 2016.)

Hargreaves DS, Viner RM (2012) Children's and young people's experience of the National Health Service in England: a review of national surveys 2001-2011. Archives of Disease in Childhood. 97, 7,661-666.

Healthcare Quality Improvement Partnership (2015) HQIP Case Study: Involving Children and Young People for Quality Improvement. www.hqip.org.uk/ public/cms/253/625/19/337/Case\%20 Study\%20-\%20NHS\%2OYouth\%20 Forum $\% 20$ - 20 Insight $\% 20$ for $\% 20$ Healthcare\%20Quality\%20Improvement. pdf?realName $=2$ X3J21.pdf (Last accessed: 12 August 2016.)

Healthwatch England (2013) Creating a Children and Young People Friendly Local Healthwatch. www.healthwatch.co.uk/sites/ healthwatch.co.uk/files/healthwatch_child_ report_web-aw.pdf (Last accessed: 12 August 2016.)

Healthwatch (2016) About Us. http://www. healthwatch.co.uk/about-us (Last accessed: 12 August 2016.)

Hill M, Davis J, Prout A et al (2004) Moving the participation agenda forward. Children \& Society. 18, 2, 77-96.
Kennedy I (2010) Getting it Right for Children and Young People. Overcoming Cultural Barriers in the NHS so as to Meet their Needs. www.gov.uk/government/uploads/ system/uploads/attachment_data/ file/216282/dh_119446.pdf (Last accessed: 12 August 2016.)

Lansdown G (2011) Every Child's Right to be Heard: A Resource Guide on the UN Committee on the Rights of the Child General Comment No.12. www.unicef.org/french/ adolescence/files/Every_Childs_Right_to_ be_Heard.pdf (Last accessed: 12 August 2016.)

Monkey Wellbeing (2014a) NHS Institute for Innovation and Improvement Primary School Resource Pack. www.monkeywellbeing. com/nhs-institute-innovation-improvementprimary-school-resource-pack (Last accessed: 12 August 2016.)

Monkey Wellbeing (2014b) Friends and Family Test (FFT) Downloads. www. monkeywellbeing.com/friends-family-test-fftdownloads (Last accessed: 12 August 2016.)

Morse JM (1994) Designing funded qualitative research. In Denzin NK, Lincoln YS (Eds) The SAGE Handbook of Qualitative Research. Sage Publications, Thousand Oaks CA, 228.

Moule P, Goodman M (2014) Nursing Research. An Introduction. Second edition. Sage Publications, London

National Children's Bureau (2013a) Bringing Children and Young People to the Heart of Healthwatch. Reflections from LINks. www. 
ncb.org.uk/media/968116/ncb_healthwatch_ print.pdf (Last accessed: 12 August 2016.)

National Children's Bureau (2013b) Child Health in the New NHS. Results of a Survey by the National Children's Bureau and the NHS Confederation. www.ncb.org.uk/ media/1100604/child_health_survey_report_ final.pdf (Last accessed: 12 August 2016.)

NHS Choices (2015a) About the NHS: NHS Core Principles. www.nhs.uk/NHSEngland/ thenhs/about/Pages/nhscoreprinciples.aspx (Last accessed: 12 August 2016.)

NHS Choices (2015b) The NHS Family and Friends Test (FFT) www.nhs.uk/NHSEngland/ AboutNHSservices/Pages/nhs-friendsand-family-test.aspx (Last accessed: 12 August 2016.)
NHS England (2015) Youth Rights in Health Care. www.england.nhs.uk/wp-content/ uploads/2015/08/yth-rights-in-hlthcr-moreinfo.jpg (Last accessed: 22 August 2016.)

NHS England (2016) Making the Family and Friends Test Inclusive. www.england.nhs.uk/ ourwork/pe/fft/ft-inclusive (Last accessed: 12 August 2016.)

NHS England Youth Forum (2015) Join the Conversation. www.youtube.com/ watch? $v=$ f_FB8kdK2Q (Last accessed: 12 August 2016.)

Ormerod M, Newton R (2013) Construction as a career choice for young disabled people: dispelling the myths. Construction Management and Economics. 31, 8, 928-938.
Patient Experience Network (2013) Improving Patient Experience for Children and Young People. A Report Prepared by the Patient Experience Network. http:// patientexperiencenetwork.org/wp-content/ uploads/2013/11/PEN-Improving-PE-forChildren-Young-People-Report-FINALElectronic-file.pdf (Last accessed: 12 August 2016.)

Reporters' Academy (2016) Cooking up a Youth Forum. www.youtube.com/ watch?v=FU-52Dxmf3g (Last accessed: 12 August 2016.)

Stewart DW, Shamdasani PN, Rook DW (2007) Focus Groups: Theory and Practice Second edition. Sage Publications, Thousand Oaks CA.
Tisdall EKM, Davis J (2004) Making a difference? Bringing children's and young people's views into policy-making. Children \& Society. 18, 2, 131-142.

UNICEF (2005) Fact Sheet: A Summary of the Rights Under the Convention on the Rights of the Child. www.uniceforg/crc/files/ Rights_overview.pdf (Last accessed: 12 August 2016.)

Young Minds (2012) Changes to NHS Landscape Devalue Young People's Participation. www.youngminds.org.uk/news/ blog/2603_changes_to_nhs_landscape_ devalue_young_people_s_participation (Last accessed: 12 August 2016.)

\section{NursingStandard}

\section{Open access}

Are you interested in making your article available to everyone, not just RCNi subscribers? RCNi Open Access enables authors to pre-pay and make the final version of their journal article freely available to all when it's published online. This service makes your article more discoverable and can increase its overall impact on nursing practice and patient care.
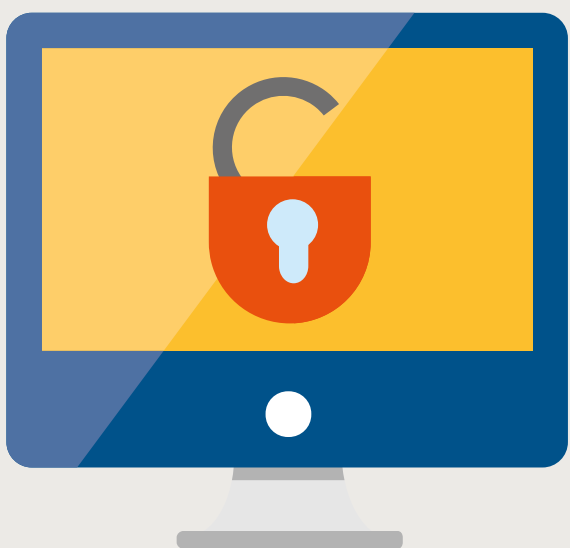